\title{
Arterial resection and reconstruction in pancreatectomy: surgical technique and outcomes
}

\author{
Qiyi Zhang ${ }^{1+}$, Jingjin $\mathrm{Wu}^{3+}$, Yang Tian ${ }^{1}$, Jixuan Duan², Yi Shao², Sheng Yan ${ }^{1 *}$ and Weilin Wang ${ }^{1 *}$
}

\begin{abstract}
Background: The outcomes in patients with pancreatic or ampulla tumors remain unsatisfactory, especially with invasion into the hepatic artery (HA) or the superior mesenteric artery (SMA). In this setting, pancreatectomy combined with arterial resection and reconstruction may offer the possibility of an en-block resection with negative margins and acceptable morbidity and mortality.

Methods: A six year retrospective review of pancreatectomies performed at our institution, included 21 patients that underwent a pancreatectomy combined with arterial resection and reconstruction. Arterial reconstruction was performed under an operating microscope. The types of arterial reconstruction included direct anastomosis, arterial transposition, and arterial bypass with a vascular graft.

Results: The surgical procedures consisted of 19 pancreaticoduodenectomies and 2 total pancreatectomies. The tumors were located at the pancreatic head $(n=10)$, whole pancreas $(n=2)$, distal common bile duct $(n=5)$, ampulla $(n=2)$ and retroperitoneum with pancreatic head involvement $(n=2)$. All operations achieved R0 resection successfully, with no intraoperative complication. Eighteen patients recovered without complications while three patients died from intraabdominal hemorrhage due to a pancreatic fistula, though notably the bleeding was not at the arterial anastomosis site. All reconstructed arteries showed adequate patency at follow-up. The median postoperative survival was 11.6 months in all the 11 patients with pancreatic adenocarcinoma.
\end{abstract}

Conclusion: Pancreatectomy combined with arterial resection and reconstruction is a feasible treatment option. The microsurgical technique is critically important to achieving a successful and patent arterial anastomosis.

\section{Background}

Currently, surgical resection is considered the only possible curative approach for pancreatic tumors [1-3]. However, postsurgical outcomes remain poor as most patients present with advanced stage disease [4]. Due to their anatomy and biological properties, many of these tumors invade the surrounding tissues, including major vessels such as the hepatic artery (HA) and the superior mesenteric artery (SMA) [5]. Under these conditions, pancreatectomy combined with major arterial resection and reconstruction is the only method for R0 resection

\footnotetext{
*Correspondence: YanS@163.com; shengyan@zju.edu.cn; wam@zju.edu.cn ${ }^{+}$Qiyi Zhang and Jingjin Wu contributed equally to this work.

'Department of Hepatobiliary and Pancreatic Surgery, The Second Affiliated Hospital, School of Medicine, Zhejiang University, Hangzhou 310003,

Zhejiang, People's Republic of China

Full list of author information is available at the end of the article
}

that can prolong postoperative survival. Some low-grade malignant tumors, such as solid-pseudopapillary tumor of the pancreas (SPT) and neuroendocrine neoplasm, may also invade the major vessels around the affected site. In these cases, $\mathrm{R} 0$ resection always requires arterial resection and reconstruction which often offers a better prognosis than patients with pancreatic adenocarcinoma.

Nevertheless, whether pancreatectomy should be combined with arterial resection and reconstruction in pancreatic tumors with major arterial involvement remains controversial [6]. Those opposed to this approach consider that arterial resection may not only add difficulty to the resection but can also influence the hepatic or intestinal arterial blood flow, thus increasing the postoperative morbidity and mortality. In contrast, some surgeons favor arterial resection because of the greater chance of achieving R0 resection in pancreatectomy [7-10]. In cases with

(c) The Author(s). 2019 Open Access This article is distributed under the terms of the Creative Commons Attribution 4.0 International License (http://creativecommons.org/licenses/by/4.0/), which permits unrestricted use, distribution, and 
major artery involvement, forcible separation of the tumor from the artery wall can cause arterial injury and even further spread of the tumor. One expert consensus statement has suggested that SMA margin is the most frequently positive during pancreatectomy [11], and R0 resection is crucial to extending patient survival [12]. If feasible, pancreatectomy combined with arterial resection and reconstruction may provide the only possibility of pancreatectomy with negative margins $[4,13]$.

Our center has a great deal of experience in living donor liver transplantation (LDLT) which requires microsurgical techniques. All hepatic arterial reconstructions are performed under an operating microscope with an extremely low rate of HA thrombosis [14]. Based on this experience, we conducted a total number of 21 pancreatectomies combined with arterial resection and reconstruction using similar techniques. The methods used in arterial reconstruction included direct anastomosis, arterial transposition, and arterial bypass with vascular graft. Herein, we share our experience and outcomes of artery resection and reconstruction in pancreatectomies.

\section{Methods}

\section{Patients}

Twenty-one patients who underwent arterial resection and reconstruction during a pancreatectomy from January 2010 to December 2015 at our center were enrolled in the study. Patients with retroperitoneal tumors involving the pancreas and cancer of the distal common bile duct (CBD) and the duodenal ampulla were also included. Arterial invasion was verified by preoperative computed tomography (CT) and intraoperative observation of all patients. A tumor was considered borderline resectable if it contacted the SMA and anatomical variants, such as accessory right hepatic artery (RHA), replaced RHA or if it involved the common hepatic artery without extension to the celiac trunk or hepatic artery bifurcation, thus allowing for safe and complete resection and reconstruction. The types of arterial reconstruction, operation time, blood loss, diagnosis, postoperative hospital stay, perioperative complications, patency of the reconstructed artery, and outcomes were assessed.

None of the 21 patients received neoadjuvant chemoradiotherapy. Preoperative informed consent was obtained from all patients. Allogeneic frozen iliac artery grafts were used following the guidelines of the Ethical Committee of our hospital, the regulations of the Organ Transplant Committee of Zhejiang Province, China and the Declaration of Helsinki.

\section{Operative technique}

Standard pancreaticoduodenectomy (PD) or total pancreatectomy (TP) was performed as previously described. When arterial invasion was suspected or the artery could not be separated from the tumor, arterial resection and reconstruction were performed.

Generally, if the length of the resected arterial segment was less than $2 \mathrm{~cm}$, direct end-to-end anastomosis was primarily considered; otherwise, arterial interposition was performed. When needed, the remnant gastroduodenal artery (GDA) from the PD resection was used as an autologous graft to reconstruct the variant RHA (Fig. 1). In the setting of a size mismatch the primary anastomosis could be perfomed in an end-to-side manner. However, arterial interposition was usually performed when none of the above methods were feasible. The autologous great saphenous vein (GSV) was the most preferred graft. In our study, size-matched allogeneic frozen iliac artery grafts were used in female patients whose GSVs were too small to match HA or SMA (Fig. 2). Arterial reconstruction was performed under an operating microscope.

A single microvascular clamp was placed on the proximal arterial stump after adequate arterial flow was confirmed. The distal artery remained free and unclamped, with backward flow detected from the portal network. The arteries were anastomosed in an end-to-end manner with interrupted sutures using 8-0 monofilament polypropylene suture (Surgipro II; Syneture, Norwalk, CT, USA), beginning with a central stitch on the posterior wall, knot tied on the outside surface. Next, the suture was advanced counterclockwise until the posterior wall was completed, with the assistant aiding visualization using both the central knot and following along each through. The distal artery was then clamped to prevent backflow, and counterclockwise suturing of the anterior wall was completed. The two penultimate stitch ends were left untied to aid the accurate insertion of the last stitch (Fig. 3). Frequent irrigation with heparinized saline solution $(25 \mathrm{U} / \mathrm{mL})$ was performed throughout the procedure to allow a clear visualization of the vascular wall. A temporary pause in ventilation was occasionally required to restrain movement during the transition of posterior to anterior wall suturing. Doppler ultrasonography was performed immediately after the completion of the arterial reconstruction. No anticoagulant or immunosuppressive drugs were used postoperatively.

\section{Follow-up}

The blood flow of the reconstructed artery was assessed by postoperative Doppler ultrasonography at 1 week postoperation, as well as at 1,6 , and 12 months. CT angiography (CTA) was carried out after 6 months, one year, and every following year. Follow-up continued through August 31, 2018.

\section{Statistics}

All data were analyzed using SPSS version 22.0 software (SPSS, Inc., Chicago, IL, USA). Categorical data were 

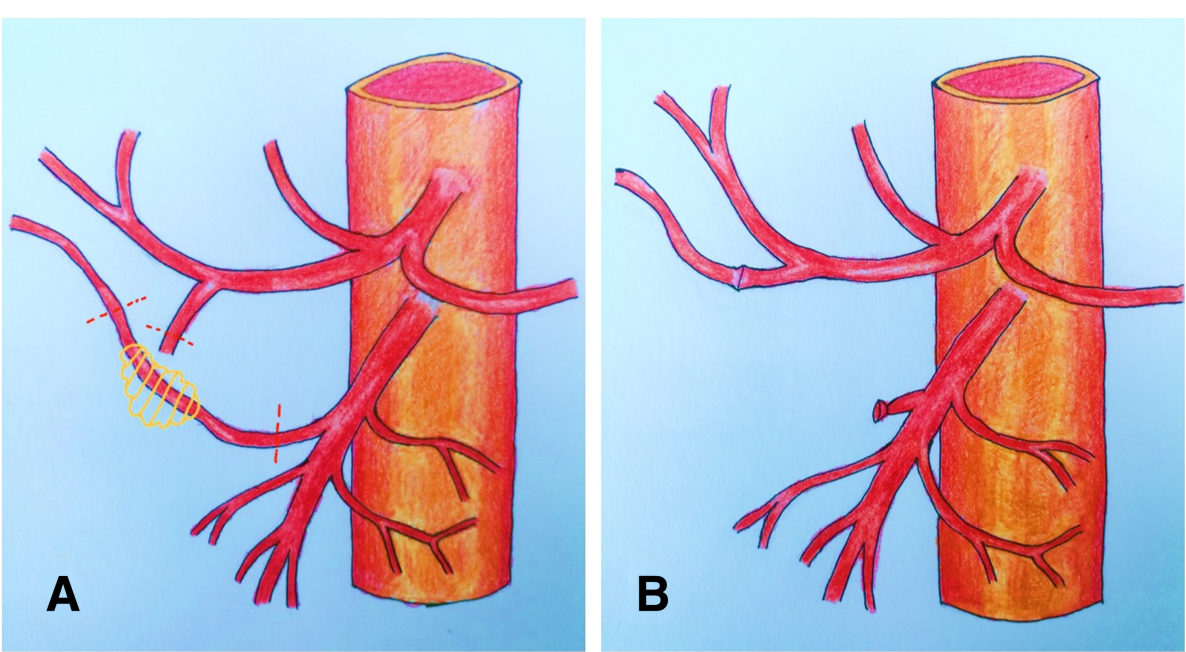

Fig. 1 a Variant right hepatic artery (RHA) from the superior mesenteric artery with tumor invasion. b Gastroduodenal artery remnant used to reconstruct the variant $\mathrm{RHA}$

expressed as a percentage and compared using Fisher's test. Continuous data were expressed as a median (range) and compared using unpaired $t$ test. Calculations and graphs were made using GraphPad Prism 5.0. $P<0.05$ was considered significant.

\section{Results}

A total number of 9 men and 12 women, with a mean age of 54 years (range 19-78), were included in our study. The surgical procedures consisted of 19 PDs and 2 TPs. All procedures achieved successful R0 resection

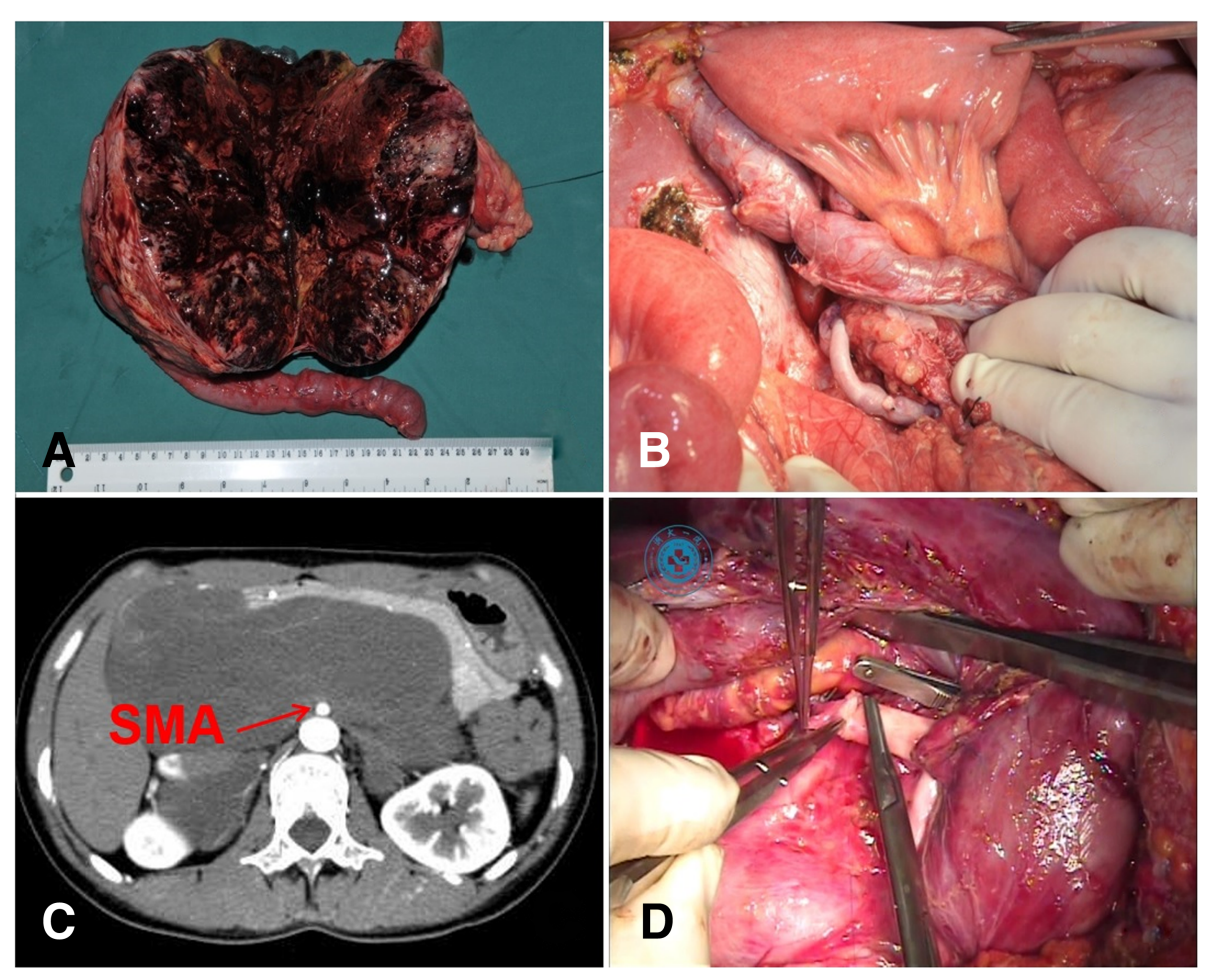

Fig. 2 a A giant solid pseudopaillary tumor $(16 \mathrm{~cm})$ located in the pancreatic head and involving the superior mesenteric artery (SMA). b SMA reconstruction using an autologous great saphenous vein. $\mathbf{c} C T$ scan of a retroperitoneal ganglioneuroma involving the pancreatic head and SMA. d SMA reconstruction using a size-matched allogeneic frozen iliac artery graft 


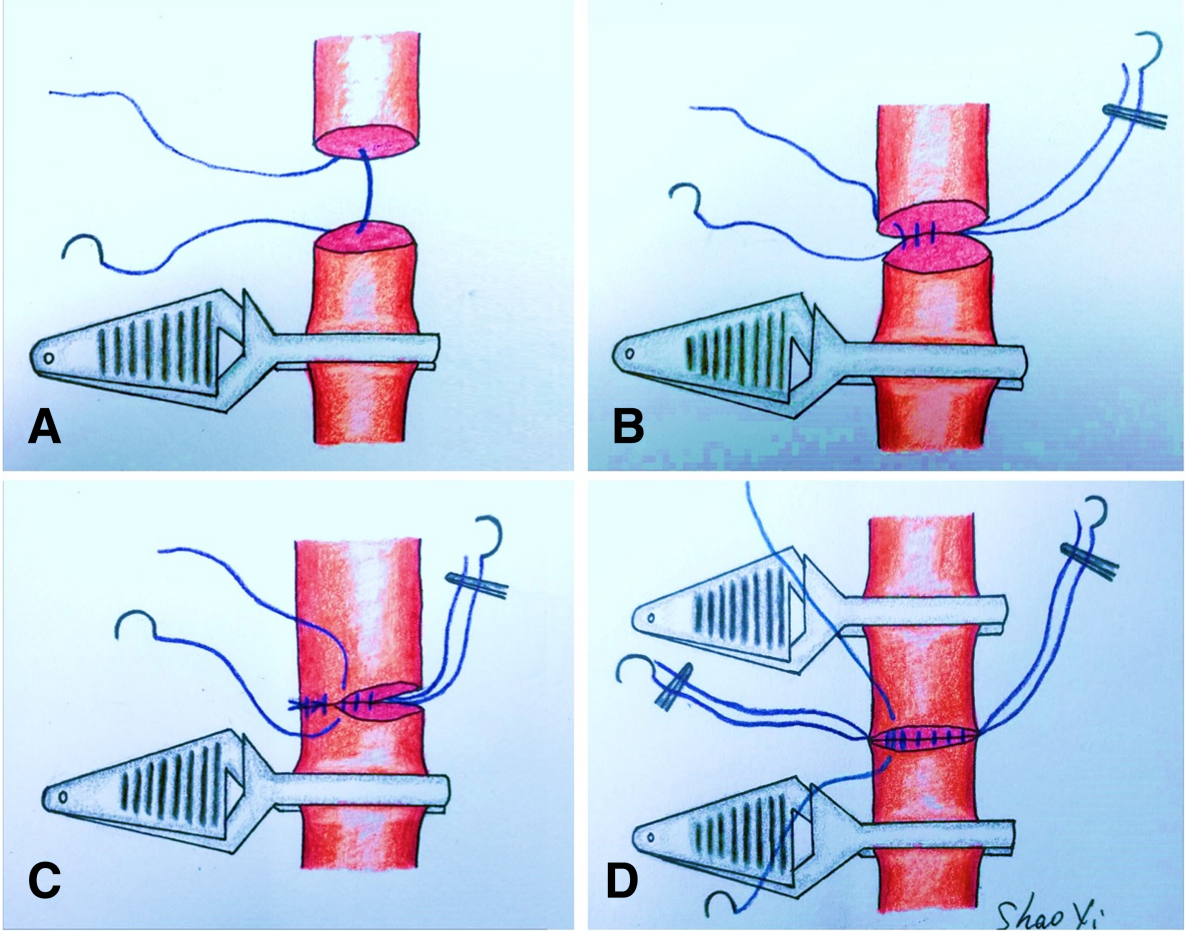

Fig. 3 a A single microvascular clamp was placed on the proximal arterial stump leaving the distal artery free unclamped. b The anastomosis was started with a central stitch on the posterior wall. Subsequent the sutures were advanced counter-clockwise, adjacent to the previous suture. $\mathbf{c}$ The first central knot was pulled by the assistant to the left side to improve visualization of the anterior wall anastomosis. $\mathbf{d}$ The distal artery was clamped and the anterior wall was completed in a similar manner

with no intraoperative complications. Operations were performed at the same institution by five surgeons each with over a decade of hepatopancreatobiliary experience. The arterial reconstruction was performed by the same microsurgical team that performed LDLT. The mean operation time was 589.2 $\mathrm{min}$ (range 187-855 $\mathrm{min}$ ), and the mean time for arterial reconstruction was $25.1 \mathrm{~min}$ (range 21-33 min). The mean blood loss was $724 \mathrm{~mL}$ (range 200-2,000 mL). The mean tumor size was $4.9 \mathrm{~cm}$ (range 1.4-16 cm). The tumors were located at the pancreatic head $(n=10)$, the whole pancreas $(n=2)$, the distal $\operatorname{CBD}(n=5)$, the ampulla $(n=2)$ and the retroperitoneum with pancreatic head involvement $(n=2)$. Fourteen patients had regional lymph node metastasis (Table 1 ).

Regional arterial resection and direct end-to-end anastomosis were used in 11 patients, whereas end-to-side anastomosis was performed in two cases. In one case, an accessory right hepatic artery (ARHA) was anastomosed to the common hepatic artery (CHA), in the second case, a replaced RHA from the SMA was anastomosed to the LHA (from the left gastric artery, LGA). In three cases, the RHA was anastomosed to the stump of the GDA. In one patient, the proper hepatic artery (PHA) was anastomosed to the LGA. Also, an allogeneic frozen iliac artery graft was interposed for the reconstruction of
SMA in one case. In the remaining three cases with the SMA involvement of the tumor, autologous great saphenous vein (GSV) was used for SMA interposition. In one of those cases, the CHA was invaded simultaneously and was reconstructed in an end-to-end manner. Nine patients underwent portal vein resection additionally, with interpositional allogeneic frozen iliac artery grafts used in three cases due to inadequate length for a direct endto-end anastomosis (Table 2).

Eighteen patients recovered and were eventually discharged after the operation. Their postoperative hospital stay was $19 \pm 7$ days without complications. Three patients died from intra-abdominal hemorrhage due to pancreatic fistulae resulting in sepsis during their hospital stay. It is worth mentioning that bleeding at the arterial anastomosis site was not found in any of the three patients, which was confirmed by digital subtraction angiography (DSA) or laparotomy. The mean follow-up duration was 16.7 months (0.3-71 months) (Table 3). Both the reconstructed arteries and veins showed adequate patency in the postoperative Doppler ultrasonography and subsequent CTA's.

Eleven patients with pancreatic adenocarcinoma who received surgery were compared with eleven patients who received chemotherapy alone from January 2012 to 
Table 1 Patient Demographics

\begin{tabular}{|c|c|}
\hline Age (year) & $54(19-78)$ \\
\hline \multicolumn{2}{|l|}{ Sex } \\
\hline Male & 9 \\
\hline Female & 12 \\
\hline Weight (Kg) & $55(38-70)$ \\
\hline Height (cm) & $164(153-178)$ \\
\hline Tumor diameter (cm) & $4.9(1.4-16.0)$ \\
\hline \multicolumn{2}{|l|}{ Tumor location } \\
\hline Pancreatic head & 10 \\
\hline Distal pancreas & 2 \\
\hline Total pancreas & 2 \\
\hline Distal CBD & 5 \\
\hline Duodenal ampulla & 2 \\
\hline \multicolumn{2}{|l|}{ Pathology } \\
\hline Adenocarcinoma & 18 \\
\hline Moderate differentiation & 15 \\
\hline Poor differentiation & 3 \\
\hline Ganglioneuroma & 2 \\
\hline SPN & 1 \\
\hline \multicolumn{2}{|l|}{ Regional metastasis } \\
\hline Yes & 14 \\
\hline No & 7 \\
\hline \multicolumn{2}{|l|}{ Distant metastasis } \\
\hline Uncertain & 4 \\
\hline No & 17 \\
\hline Operational time (min) & $589(187-855)$ \\
\hline Arterial reconstruction time (min) & $25.1(21-33)$ \\
\hline Blood loss (mL) & $723(200-2000)$ \\
\hline Post-operative hospital stay (day) & $19(8-34)$ \\
\hline
\end{tabular}

$C B D$ common bile duct, SPN solid pseudopapillary neoplasm. Data are presented as "mean (range)"

August 2018 (Table 4 and Fig. 4). The oncologic outcomes were similar between the two groups with the median survival of 11.6 months in the operative group vs. 8.5 months in the chemotherapy group, $p>0.05$.

\section{Discussion}

Fortner et al. reported no significant improvement in the postoperative outcomes for arterial resection and reconstruction in pancreatectomy [15], and pancreatic cancer with arterial involvement is considered a contraindication to resection by most surgeons. However, limited studies have reported more promising outcomes [16-19]. For instance, Karyn et al. reviewed twelve cases with pancreatic cancer that underwent a pancreatectomy with hepatic artery or celiac artery resection and established a median survival of 17 months and a 3-year survival of $17 \%$ [20].
Moreover, Hodaka et al. concluded that patients with the possibility of R0 surgery might benefit from arterial resection and reconstruction. In their study, the median survival times for $\mathrm{R} 0$ and $\mathrm{R} 1 / \mathrm{R} 2$ resections were thirteen and six months, respectively [21]. Additionally, Mollberg et al. analyzed five investigations with comparative data and found significant improvements in the 1-year (OR: 4.28; $P<0.0001)$ and 2-year (OR: 19.65; $P<0.0001)$ survival in patients with arterial resection compared with patients without [22]. Even though pancreatic cancer resections are associated with high mortality and morbidity, pancreatectomy combined with arterial resection may prolong the survival in select patients.

The pancreas, though retroperitoneal, lies adjacent to major vessels such as the celiac artery, HA and SMA. Furthermore, HA variants have been reported in as many as 20 to $50 \%$ of patients [23]. Hiatt et al. reported $10.6 \%$ replaced or accessory RHA originating from the SMA. Especially in this setting of arterial variants, major vessel invasion by the pancreatic tumor can be found in nearly 45\% [24]. Moreover, lymph node metastases occur frequently even in patients with early-stage pancreatic cancer [25]. This makes resection of the involved artery necessary for radical lymphadenectomy and enbloc resection.

In our series, the diameters of the HA and SMA were $2-3 \mathrm{~mm}$ and $6-8 \mathrm{~mm}$, respectively. Thinner arterial walls secondary to tumor invasion, increases the risk for arterial thrombosis, anastomotic bleeding, and stenosis after arterial reconstruction. The incidence of the above complications affects the blood flow to the liver and intestines, which can lead to hepatic failure or intestinal ischemia. Many studies have concluded that microsurgical techniques can considerably decrease the risk of hepatic arterial thrombosis after LDLT [26]. The HA reconstruction technique can also be applied to the arterial reconstruction in pancreatoduodenectomy. Consequently, this microsurgical technique was important for achieving a safe and effective arterial anastomosis.

In the present study, twenty-one patients who underwent pancreatectomy with resection and reconstruction of a major artery were reviewed. No intraoperative complications were observed in any of these cases. Although three patients died in the hospital due to intraabdominal hemorrhage and sepsis after the operation, none of these complications were attributed to the arterial reconstruction given DSA and exploratory laparotomy results.

Two critical points were the length and diameter of the involved arteries. We have previously observed that direct end-to-end anastomosis is feasible when the length of the resected arterial segment is less than $2 \mathrm{~cm}$ (data not shown). Otherwise, arterial transposition or arterial bypass was a better option. The choice of the 
Table 2 Surgical Outcomes

\begin{tabular}{|c|c|c|c|c|c|}
\hline Case & Surgery & Invaded artery & Arterial reconstruction & Venous reconstruction & Arterial anatomy \\
\hline 1 & PD & ARHA & $\mathrm{ARHA}-\mathrm{CHA}$ & PV-SMV & ARHA from SMA \\
\hline 2 & PD & RHA & RHA-GDA & No & LHA from LGA; RHA from SMA \\
\hline 3 & PD & RHA & RHA-LHA & No & LHA from LGA; RHA from SMA \\
\hline 4 & TP & $\mathrm{CHA} \& \mathrm{PHA}$ & $\mathrm{PHA}-\mathrm{CHA}$ & SMV-SMV & Normal \\
\hline 5 & PD & RHA & RHA-GDA & No & RHA from GDA \\
\hline 6 & PD & CHA \& PHA & $\mathrm{PHA}-\mathrm{CHA}$ & $S V+S M V-" Y "$ graft- PV & Normal \\
\hline 7 & PD & $\mathrm{CHA}$ & $\mathrm{CHA}-\mathrm{CHA}$ & No & SMA from Celiac axis, SA from aorta \\
\hline 8 & TP & RHA & RHA-RHA & PV-PV & $\mathrm{RHA}$ from $\mathrm{CHA}$ \\
\hline 9 & PD & PHA & PHA-LGA & $S V+S M V-~ " Y " ~ g r a f t-P V$ & Normal \\
\hline 10 & PD & $\mathrm{CHA}$ & $\mathrm{CHA}-\mathrm{CHA}$ & No & Normal \\
\hline 11 & PD & RHA & $\mathrm{RHA}-\mathrm{RHA}$ & No & Normal \\
\hline 12 & PD & PHA & $\mathrm{PHA}-\mathrm{CHA}$ & PV-PV; SMV- "Y" graft-SMV & Normal \\
\hline 13 & PD & PHA & $\mathrm{PHA}-\mathrm{CHA}$ & No & Normal \\
\hline 14 & PD & RHA & RHA-GDA & No & RHA from SMA \\
\hline 15 & PD & CHA \& PHA & $\mathrm{PHA}-\mathrm{CHA}$ & PV-PV & Normal \\
\hline 16 & PD & SMA & SMA-graft-SMA & No & SMA from Celiac axis; LGA from aorta \\
\hline 17 & PD & CHA \& PHA & $\mathrm{PHA}-\mathrm{CHA}$ & PV-PV & Normal \\
\hline 18 & PD & $\mathrm{RHA}$ & RHA-GDA & PV-PV & Normal \\
\hline 19 & PD & SMA & SMA-GSV-SMA & No & Normal \\
\hline 20 & PD & SMA & SMA-GSV-SMA & No & Normal \\
\hline 21 & PD & CHA \& SMA & CHA-CHA; SMA-GSVSMA & No & Normal \\
\hline
\end{tabular}

$P D$ pancreaticoduodenectomy, $T P$ total pancreatectom, DP distal pancreatectomy, $A R H A$ accessory right hepatic artery, $C H A$ common hepatic artery, $P H A$ proper hepatic artery, RHA right hepatic artery, LHA left hepatic artery, GDA gastroduodenal artery, LGA left gastric artery, SMA superior mesenteric artery, SA splenic artery, $P V$ portal vein, SMV superior mesenteric vein, GSV great saphenous vein. Graft: allogeneic frozen iliac vessel

proximal artery for the arterial transposition is diverse. Theoretically, the stump of the HA or SMA can be anastomosed with any of the proximal arteries, provided their lengths and diameters were suitable. The GDA is routinely resected in $\mathrm{PD}$, and its stump may be an appropriate option to reconstruct the RHA [27, 28], especially in cases where the RHA arises from the SMA. Some surgeons have also used the splenic artery (SA) transposition to reconstruct the HA or SMA [29-31]. However, there is the potential for SA dissociation and an added risk of splenic due to the multiple SA branches. Hence, the SA is seldom utilized for the HA or SMA reconstruction in pancreatectomies.

Additionally, vascular bypass offers an important option for arterial reconstruction [32]. GSV has been widely used in coronary artery bypass grafting. With advantages such as increased success rate and sufficient length, the GSV has primarily been considered the graft of choice for the arterial reconstruction in pancreatectomy. Allogeneic vessel graft is another alternatives for revascularization. At our center, frozen allogeneic iliac arteries are frequently utilized for venous reconstruction (segment V/VIII) of the liver graft in LDLT. Based on this experience, we used an allogeneic frozen iliac artery in one case and autologous GSV in three cases for the SMA reconstruction. Just as there was a wide range of variations to these methods, surgeons should determine the best choice based on the peculiarities of each patient situation.

As the vascular reconstruction procedure is timeconsuming, surgeons should be cautious of the artery occlusion time. Bin-Li et al. reported a HA- and SMAocclusion time during revascularization of 38-50 min and 35-50 min, respectively. No patients who underwent PD with arterial reconstruction experienced liver or small bowel ischemia [17]. In the present study, the arterial anastomosis took $25.1 \mathrm{~min}(21-33 \mathrm{~min})$ to complete, without any complications. When the PV and HA needed to be reconstructed simultaneously, the SMA was always temporarily occluded to prevent congestion of the small intestine if HA-occlusion exceeded one hour.

Multimodality treatment approaches have become routine for pancreatic cancer therapy [33]. Neoadjuvant chemotherapy, which may be superior at improving the R0 resection rate and assessment of the sensitivity to chemotherapeutic drugs, has attracted substantial attention [34, 35]. Our series was conducted from 2010 to 
Table 3 Patient Outcomes and Disease Pathologies

\begin{tabular}{|c|c|c|c|c|c|c|c|c|c|c|}
\hline Case & Sex & $\begin{array}{l}\text { Age } \\
\text { (year) }\end{array}$ & Location & $\begin{array}{l}\text { Diameter } \\
(\mathrm{cm})\end{array}$ & Pathology & Differentiation & $\begin{array}{l}\text { Regional } \\
\text { metastasis }\end{array}$ & $\begin{array}{l}\text { Post-operative } \\
\text { stay (day) }\end{array}$ & Complication & $\begin{array}{l}\text { Outcome (months, } \\
\text { cause of death) }\end{array}$ \\
\hline 1 & M & 52 & Distal CBD & 4 & Adenocarcinoma & Moderately & Yes & 19 & None & $\begin{array}{l}\text { Deceased ( } 25.9, \\
\text { recurrence) }\end{array}$ \\
\hline 2 & $\mathrm{~F}$ & 57 & Distal CBD & 1.5 & Adenocarcinoma & Moderately & Yes & 17 & None & $\begin{array}{l}\text { Deceased ( } 27.5, \\
\text { recurrence) }\end{array}$ \\
\hline 3 & $\mathrm{~F}$ & 57 & $\begin{array}{l}\text { Duodenal } \\
\text { ampulla }\end{array}$ & 2 & Adenocarcinoma & Moderately & Yes & 34 & None & $\begin{array}{l}\text { Deceased (9.7, } \\
\text { recurrence) }\end{array}$ \\
\hline 4 & M & 49 & Whole pancreas & 6 & Adenocarcinoma & Moderately & Yes & 25 & None & $\begin{array}{l}\text { Deceased (12.9, } \\
\text { recurrence) }\end{array}$ \\
\hline 5 & M & 69 & Uncinate process & 5 & Adenocarcinoma & Poorly & Yes & 20 & None & $\begin{array}{l}\text { Deceased (3.1, } \\
\text { cerebral infarction) }\end{array}$ \\
\hline 6 & $\mathrm{~F}$ & 67 & Pancreatic head & 4 & Adenocarcinoma & Moderately & Yes & 17 & None & $\begin{array}{l}\text { Deceased (10, } \\
\text { recurrence) }\end{array}$ \\
\hline 7 & M & 65 & Distal CBD & 4.5 & Adenocarcinoma & Moderately & Yes & - & Bleeding; sepsis & $\begin{array}{l}\text { Deceased ( } 0.3, \\
\text { bleeding; infection) }\end{array}$ \\
\hline 8 & $F$ & 47 & Whole pancreas & 3 & Adenocarcinoma & Moderately & Yes & 34 & None & $\begin{array}{l}\text { Deceased (1.8, } \\
\text { chemotherapy } \\
\text { related) }\end{array}$ \\
\hline 9 & M & 49 & Pancreatic head & 4 & Adenocarcinoma & Moderately & Yes & 14 & None & $\begin{array}{l}\text { Deceased (37.7, } \\
\text { recurrence) }\end{array}$ \\
\hline 10 & M & 67 & Distal CBD & 2 & Adenocarcinoma & Moderately & Yes & 22 & None & Lost (0.7) \\
\hline 11 & $\mathrm{~F}$ & 54 & $\begin{array}{l}\text { Duodenal } \\
\text { ampulla }\end{array}$ & 2 & Adenocarcinoma & Poorly & Yes & 11 & None & $\begin{array}{l}\text { Deceased (13.4, } \\
\text { recurrence) }\end{array}$ \\
\hline 12 & $\mathrm{~F}$ & 53 & Pancreatic head & 4 & Adenocarcinoma & Moderately & Yes & 12 & None & $\begin{array}{l}\text { Deceased (11.6, } \\
\text { recurrence) }\end{array}$ \\
\hline 13 & M & 78 & Pancreatic head & 3 & Adenocarcinoma & Moderately & No & 20 & None & $\begin{array}{l}\text { Deceased (10, } \\
\text { gastroplegia) }\end{array}$ \\
\hline 14 & $\mathrm{~F}$ & 56 & Pancreatic head & 3 & Adenocarcinoma & Moderately & Yes & 22 & None & $\begin{array}{l}\text { Deceased (17, } \\
\text { recurrence) }\end{array}$ \\
\hline 15 & M & 75 & Pancreatic head & 4 & Adenocarcinoma & Poorly & No & - & Bleeding; sepsis & $\begin{array}{l}\text { Deceased (0.6, } \\
\text { bleeding; infection) }\end{array}$ \\
\hline 16 & M & 55 & Distal CBD & 1.4 & Adenocarcinoma & Moderately & No & - & Bleeding; sepsis & $\begin{array}{l}\text { Deceased ( } 0.4, \\
\text { bleeding; infection) }\end{array}$ \\
\hline 17 & $F$ & 60 & Uncinate process & 4 & Adenocarcinoma & Moderately & Yes & 15 & None & $\begin{array}{l}\text { Deceased (12.5, } \\
\text { recurrence) }\end{array}$ \\
\hline 18 & $\mathrm{~F}$ & 30 & Uncinate process & 4 & Adenocarcinoma & Moderately & No & 16 & None & $\begin{array}{l}\text { Deceased (11.8, } \\
\text { recurrence) }\end{array}$ \\
\hline 19 & $\mathrm{~F}$ & 49 & $\begin{array}{l}\text { Retroperitoneum } \\
\text { with pancreatic } \\
\text { head involvement }\end{array}$ & 11 & Ganglioneuroma & - & No & 21 & $\begin{array}{l}\text { Pancreatic } \\
\text { fistula (A) }\end{array}$ & Alive (60.6) \\
\hline 20 & $\mathrm{~F}$ & 19 & Pancreatic head & 16 & SPT & - & No & 27 & None & $\begin{array}{l}\text { Deceased (11.6, } \\
\text { recurrence) }\end{array}$ \\
\hline 21 & $\mathrm{~F}$ & 23 & $\begin{array}{l}\text { Retroperitoneum } \\
\text { with pancreatic } \\
\text { head involvement }\end{array}$ & 15 & Ganglioneuroma & - & No & 13 & None & Alive (71) \\
\hline
\end{tabular}

$M$ male, $F$ female, $C B D$ common bile duct, SPT solid pseudopapillary tumor

2015. Gemcitabine was the first line therapy for neoadjuvant chemotherapy for locally advanced pancreatic cancer during that time, however, its ORR was unsatisfactory compared with FOLFIRINOX or gemcitabine+albumin-bound paclitaxel regimens. Secondly, most patients in China diagnosed with advanced pancreatic cancer prefer radical resection due to the financial burden associated with the chemotherapeutic regimen. One limitation of this study is the relatively small sample size. More patients are required to expand the research foundation and our understanding in this field. 
Table 4 Outcomes of Patient with Pancreatic Adenocarcinoma

\begin{tabular}{|c|c|c|c|}
\hline & Operative Group & Chemotherapy Group & $P$ value \\
\hline Total Patients & 11 & 11 & \\
\hline Age, mean (yr) & $58(30-78)$ & $61(46-81)$ & 0.5004 \\
\hline Sex & & & 1.000 \\
\hline Male & $5(45.6 \%)$ & $6(54.4 \%)$ & \\
\hline Female & $6(54.4 \%)$ & $5(45.6 \%)$ & \\
\hline Tumor diameter, mean $(\mathrm{cm})$ & $4(3-6)$ & $4.1(2.5-6)$ & 0.7399 \\
\hline TNM stage & III & III & \\
\hline Tumor location & & & 0.0841 \\
\hline Pancreatic head & $8(72.7 \%)$ & $6(54.4 \%)$ & \\
\hline Distal pancreas & $1(9.1 \%)$ & $5(45.6 \%)$ & \\
\hline Total pancreas & $2(18.2 \%)$ & $0(0 \%)$ & \\
\hline Chemotherapy protocols & & & 0.0292 \\
\hline GEM & $7(63.6 \%)$ & $2(18.2 \%)$ & \\
\hline GEMOX & $0(0 \%)$ & $2(18.2 \%)$ & \\
\hline GS & $1(9.1 \%)$ & $5(45.6 \%)$ & \\
\hline mFOLFIRINOX & $0(0 \%)$ & $1(9.1 \%)$ & \\
\hline$A G$ & $0(0 \%)$ & $1(9.1 \%)$ & \\
\hline None & $3(27.3 \%)$ & $0(0 \%)$ & \\
\hline Median Survival (mo) & $11.7(0.6-37.7)$ & $11.1(0.7-36.9)$ & 0.922 \\
\hline
\end{tabular}

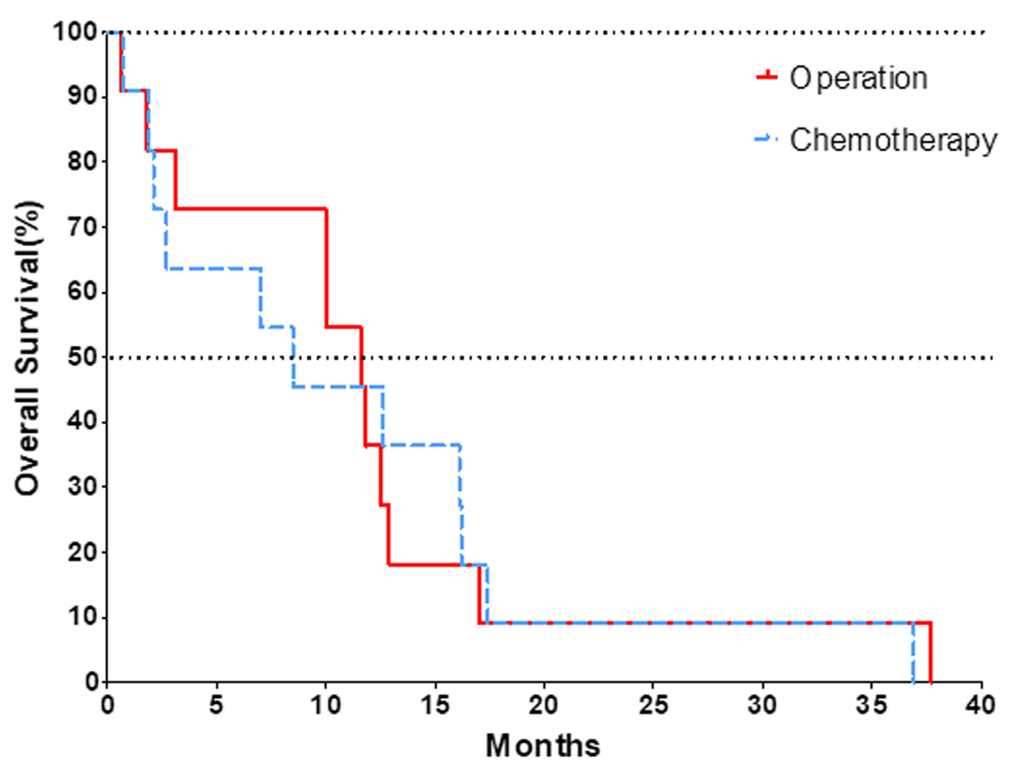

Fig. 4 The median survival time was 11.6 months in operative group vs. 8.5 months in the chemotherapy group, $p>0.05$ 


\section{Conclusion}

Pancreatectomy combined with arterial resection and reconstruction is a feasible treatment option, and can be considered for select patients. Microsurgical technique is critically important for a successful and patent arterial anastomosis.

\begin{abstract}
Abbreviations
ARHA: Accessory right hepatic artery; CBD: Common bile duct; CHA: Common hepatic artery; CT: Computed tomography; CTA: CT angiography; DSA: Digital subtraction angiography; GDA: Gastroduodenal artery; GSV: Great saphenous vein; HA: Hepatic artery; LDLT: Living donor liver transplantation; LGA: Left gastric artery; LHA: Left hepatic artery; PD: Pancreaticoduodenectomy; PHA: Proper hepatic artery; RHA: Right hepatic artery; SMA: Superior mesenteric artery; SPT: Solid-pseudopapillary tumor of the pancreas; TP: Total pancreatectomy
\end{abstract}

\section{Acknowledgments}

Not applicable.

\section{Authors' contributions}

QZ and JW designed the study and performed statistical analysis. JW, YT, JD and YS searched the institutional database and reviewed the data. YS performed the drawings and pictures. JW drafted the manuscript; QZ and SY contributed to revise the manuscript. SY and WW was responsible for the study conception, design, data, analysis and drafting of the manuscript. All authors read and approved the final manuscript.

\section{Funding}

This project was supported by the National Natural Science Foundation of China (No.81572307, 81572975) and the National Key R \& D project(2017YFC0114102).

\section{Availability of data and materials}

The data that support the findings of this study are available from Division of Hepatobiliary and Pancreatic Surgery, Department of Surgery, however, restrictions apply to the availability of this data; which was used under license for the current study, therefore are not publicly available. Data are however available from the authors upon reasonable request, with permission from the Division of Hepatobiliary and Pancreatic Surgery, Department of Surgery.

\section{Ethics approval and consent to participate}

This study protocol was reviewed and approved by the Ethics Committee of the First Affiliated Hospital, Zhejiang University School of Medicine.

\section{Consent for publication}

Written informed consent for publication was obtained from all participants.

\section{Competing interests}

The authors declare that they have no competing interests.

\section{Author details}

'Department of Hepatobiliary and Pancreatic Surgery, The Second Affiliated Hospital, School of Medicine, Zhejiang University, Hangzhou 310003, Zhejiang, People's Republic of China. ${ }^{2}$ Division of Hepatobiliary and Pancreatic Surgery, Department of Surgery, The First Affiliated Hospital, Zhejiang University School of Medicine, Hangzhou, China. ${ }^{3}$ General Surgery, The Fourth Affiliated Hospital, Zhejiang University School of Medicine, Yiwu, China.

\section{Received: 1 November 2018 Accepted: 12 July 2019}

\section{Published online: 10 October 2019}

\section{References}

1. Maley WR, Yeo CJ. Vascular resections during the Whipple procedure. Adv Surg. 2017;51(1):41-63.

2. Vera R, Diez L, Martin Perez E, Plaza JC, Sanjuanbenito A, Carrato A. Surgery for pancreatic ductal adenocarcinoma. Clin Transl Oncol. 2017;19(11): 1303-11.
3. Ravikumar R, Holroyd D, Fusai G. Is there a role for arterial reconstruction in surgery for pancreatic cancer? World J Gastrointest Surg. 2013;5(3):27-9.

4. Kasumova GG, Conway WC, Tseng JF. The role of venous and arterial resection in pancreatic Cancer surgery. Ann Surg Oncol. 2018;25(1):51-8.

5. Matsumoto T, Kubota K, Aoki T, Shimizu T, Mori S, Kato M, et al. A novel approach for hepatic arterial reconstruction after Total pancreatectomy with common hepatic artery resection using inferior phrenic artery. Dig Surg. 2018;36(2):99-103.

6. Adham M, Mirza DF, Chapuis F, Mayer AD, Bramhall SR, Coldham C, et al. Results of vascular resections during pancreatectomy from two European centres: an analysis of survival and disease-free survival explicative factors. HPB (Oxford). 2006;8(6):465-73.

7. Vicente E, Quijano Y, lelpo B, Duran H. Total pancreatoduodenectomy en bloc with superior mesenteric artery and vein resection after gemcitabine and nab-paclitaxel neoadjuvancy. Surg Oncol. 2017;26(3):276-7.

8. Sato T, Saiura A, Inoue Y, Takahashi Y, Arita J, Takemura N. Distal pancreatectomy with En bloc resection of the celiac Axis with preservation or reconstruction of the left gastric artery in patients with pancreatic body Cancer. World J Surg. 2016;40(9):2245-53.

9. Hicks CW, Burkhart RA, Weiss MJ, Wolfgang CL, Cameron AM, Pawlik TM. Management of Type 9 hepatic arterial anatomy at the time of Pancreaticoduodenectomy: considerations for preservation and reconstruction of a completely replaced common hepatic artery. J Gastrointest Surg. 2016;20(7):1400-4.

10. Gong H, Ma R, Gong J, Cai C, Song Z, Xu B. Distal pancreatectomy with En bloc celiac Axis resection for locally advanced pancreatic Cancer: a systematic review and meta-analysis. Medicine. 2016;95(10):e3061.

11. Katz MH, Lee JE, Pisters PW, Skoracki R, Tamm E, Fleming JB. Retroperitoneal dissection in patients with borderline resectable pancreatic cancer: operative principles and techniques. J Am Coll Surg. 2012;215(2):e11-8.

12. Evans DB, Farnell MB, Lillemoe KD, Vollmer C Jr, Strasberg SM, Schulick RD. Surgical treatment of resectable and borderline resectable pancreas cancer: expert consensus statement. Ann Surg Oncol. 2009;16(7):1736-44.

13. Christians KK, Pilgrim CH, Tsai S, Ritch P, George B, Erickson B, et al. Arterial resection at the time of pancreatectomy for cancer. Surgery. 2014;155(5): 919-26.

14. Yan S, Zhang QY, Yu YS, He JJ, Wang WL, Zhang M, et al. Microsurgical reconstruction of hepatic artery in living donor liver transplantation: experiences and lessons. Hepatobiliary Pancreat Dis Int. 2009;8(6):575-80.

15. Fortner JG. Regional pancreatectomy for cancer of the pancreas, ampulla, and other related sites. Tumor staging and results. Ann Surg. 1984;199(4): 418-25.

16. Sato $T$, Inoue $Y$, Takahashi $Y$, Mise $Y$, Ishizawa T, Tanakura K, et al. Distal pancreatectomy with celiac Axis resection combined with reconstruction of the left gastric artery. J Gastrointest Surg. 2017;21(5):910-7.

17. Li B, Chen FZ, Ge XH, Cai MZ, Jiang JS, Li JP, et al. Pancreatoduodenectomy with vascular reconstruction in treating carcinoma of the pancreatic head. Hepatobiliary Pancreat Dis Int. 2004;3(4):612-5

18. Allendorf JD, Bellemare S. Reconstruction of the replaced right hepatic artery at the time of pancreaticoduodenectomy. J Gastrointest Surg. 2009; 13(3):555-7.

19. Martin RC 2nd, Scoggins CR, Egnatashvili V, Staley CA, McMasters KM, Kooby DA. Arterial and venous resection for pancreatic adenocarcinoma: operative and long-term outcomes. Archives of surgery (Chicago, III : 1960). 2009; 144(2):154-9.

20. Stitzenberg KB, Watson JC, Roberts A, Kagan SA, Cohen SJ, Konski AA, et al. Survival after pancreatectomy with major arterial resection and reconstruction. Ann Surg Oncol. 2008;15(5):1399-406.

21. Amano H, Miura F, Toyota N, Wada K, Katoh K, Hayano K, et al. Is pancreatectomy with arterial reconstruction a safe and useful procedure for locally advanced pancreatic cancer? J Hepato-Biliary-Pancreat Surg. 2009; 16(6):850-7.

22. Mollberg N, Rahbari NN, Koch M, Hartwig W, Hoeger Y, Buchler MW, et al. Arterial resection during pancreatectomy for pancreatic cancer: a systematic review and meta-analysis. Ann Surg. 2011;254(6):882-93.

23. Amano H, Miura F, Toyota N, Wada K, Katoh K, Hayano K, et al. Pancreatectomy with reconstruction of the right and left hepatic arteries for locally advanced pancreatic cancer. J Hepato-Biliary-Pancreat Surg. 2009; 16(6):777-80.

24. Hiatt JR, Gabbay J, Busuttil RW. Surgical anatomy of the hepatic arteries in 1000 cases. Ann Surg. 1994;220(1):50-2. 
25. Alexakis N, Halloran C, Raraty M, Ghaneh P, Sutton R, Neoptolemos JP. Current standards of surgery for pancreatic cancer. Br J Surg. 2004:91(11): 1410-27.

26. Moon DB, Lee SG, Kim KH. Total hepatectomy, pancreatoduodenectomy, and living donor liver transplantation using innovative vascular reconstruction for unresectable cholangiocarcinoma. Transpl Int. 2015;28(1): 123-6.

27. Sarmiento JM, Panneton JM, Nagorney DM. Reconstruction of the hepatic artery using the gastroduodenal artery. Am J Surg. 2003;185(4):386-7.

28. Kulkarni GV, Malinowski M, Hershberger R, Aranha GV. Proper hepatic artery reconstruction with gastroduodenal artery transposition during pancreaticoduodenectomy. Perspect Vasc Surg Endovasc Ther. 2013;25(3-4): 69-72.

29. Seelig MH, Belyaev O, Uhl W. Reconstruction of the common hepatic artery at the time of total pancreatectomy using a splenohepatic bypass. J Gastrointest Surg. 2010;14(5):913-5.

30. Mukherjee D, Hendershot KM. Splenic artery-to-superior mesenteric artery bypass for chronic mesenteric ischemia--a case report. Vasc Endovasc Surg 2004:38(5):465-8.

31. Hackert T, Weitz J, Buchler MW. Splenic artery use for arterial reconstruction in pancreatic surgery. Langenbeck's Arch Surg. 2014;399(5):667-71.

32. Lai ECS. Vascular resection and reconstruction at pancreaticoduodenectomy: technical issues. Hepatobiliary Pancreat Dis Int. 2012;11(3): $234-42$

33. Younan G, Tsai S, Evans DB, Christians KK. Techniques of vascular resection and reconstruction in pancreatic Cancer. Surg Clin North Am. 2016:96(6): 1351-70.

34. Bassi C, Stocken DD, Olah A, Friess H, Buckels J, Hickey H, et al. Influence of surgical resection and post-operative complications on survival following adjuvant treatment for pancreatic cancer in the ESPAC-1 randomized controlled trial. Dig Surg. 2005;22(5):353-63.

35. Katz $\mathrm{MH}$, Wang $\mathrm{H}$, Balachandran A, Bhosale $\mathrm{P}$, Crane $\mathrm{CH}$, Wang $\mathrm{X}$, et al. Effect of neoadjuvant chemoradiation and surgical technique on recurrence of localized pancreatic cancer. J Gastrointest Surg. 2012;16(1):68-78 discussion -9 .

\section{Publisher's Note}

Springer Nature remains neutral with regard to jurisdictional claims in published maps and institutional affiliations.

Ready to submit your research? Choose BMC and benefit from:

- fast, convenient online submission

- thorough peer review by experienced researchers in your field

- rapid publication on acceptance

- support for research data, including large and complex data types

- gold Open Access which fosters wider collaboration and increased citations

- maximum visibility for your research: over $100 \mathrm{M}$ website views per year

At $\mathrm{BMC}$, research is always in progress.

Learn more biomedcentral.com/submissions 